\title{
Characterization of $(\mathrm{CA})_{n}$ microsatellites with degenerate sequencing primers
}

\author{
D.L.Browne and M.Litt* \\ Departments of Molecular and Medical Genetics and Biochemistry and Molecular Biology, Oregon \\ Health Sciences University, Portland, OR 97201-3098, USA
}

Submitted October 29, 1991

Construction of DNA clones which allow determination of sequences flanking $(\mathrm{CA})_{\mathrm{n}}$ microsatellites $(1,2)$ is the most laborious part of developing these genetic markers. When using the common mp 18/19 cloning vectors and sequencing primers, best sequencing results are obtained when the $(\mathrm{CA})_{\mathrm{n}}$ microsatellite is $50-200 \mathrm{bp}$ from one end of a cloned restriction fragment. In order to determine sequences which are inaccessible with vector-derived primers, we have used a set of degenerate sequencing primers which anneal directly to $(\mathrm{CA})_{\mathrm{n}}$ microsatellites. Twelve-fold degeneracy at the $3^{\prime}$ end of each of these primers prevents elongation of primers which have annealed out of register.

The primers $(\mathrm{CA})_{7}-(\mathrm{A} / \mathrm{G} / \mathrm{T})-\mathrm{G}, \quad(\mathrm{CA})_{7}-(\mathrm{A} / \mathrm{G} / \mathrm{T})-\mathrm{A}, \quad(\mathrm{C}-$ A ) ${ }_{7}-(\mathrm{A} / \mathrm{G} / \mathrm{T})-\mathrm{T}, \quad(\mathrm{CA})_{7}-(\mathrm{A} / \mathrm{G} / \mathrm{T})-\mathrm{C}$ and $(\mathrm{GT})_{7}-(\mathrm{T} / \mathrm{A} / \mathrm{C})-\mathrm{G}$, $(\mathrm{GT})_{7}-(\mathrm{T} / \mathrm{A} / \mathrm{C})-\mathrm{A},(\mathrm{GT})_{7}-(\mathrm{T} / \mathrm{A} / \mathrm{C})-\mathrm{T},(\mathrm{GT})_{7}-(\mathrm{T} / \mathrm{A} / \mathrm{C})-\mathrm{C}$ were synthesised on an Applied Biosystems 391 DNA synthesizer. Equimolar amounts of the four primers which constitute a set [(CA) or (GT)] were mixed. Double-stranded plasmid DNA was sequenced using the protocols supplied with the Sequenase ${ }^{T M}$ kit except that each annealing reaction contained 25 pmol primer. Twelve subclones containing $(C A)_{n}$ microsatellites with insert sizes in the range from 2 to $9 \mathrm{~kb}$ were sequenced with each of the degenerate primer mixes. In 11 cases flanking sequences approximately $30-100 \mathrm{nt}$ from the microsatellites were obtained with at least one of the mixes. Unique primers designed from these sequences were used to determine the sequences of the microsatellites and other flanking sequences; in some cases they were also used later as PCR primers to amplify fragments of genomic DNA. The figure shows typical results obtained with a $(\mathrm{CA})_{\mathrm{n}}$-containing subclone.

Another set of degenerate primers based upon (AC) and (TG) repeats can be used in this method. However, a review of the sequences of $86(\mathrm{CA})_{\mathrm{n}}$ repeats determined using vector-based primers showed that $76(88 \%)$ had AT base pairs at one or both ends of the repeat, so that only $12 \%$ of repeats would require (AC) and TG) based primers. This is consistent with the rate of success we have had using only the (CA)- and (GT)-based primers.

A similar approach to obtaining sequences flanking $(\mathrm{CA})_{\mathrm{n}}$ microsatellites was reported by Yuille et al. (4). However, our method differs from theirs in the following respect. To sequence one of the two strands, they used six sets of sequencing reactions, each with a single non-degenerate primer. This requires 24 gel lanes. In contrast, we attempt to obtain sequence from both of the strands by running two sets of reactions using degenerate primer mixes. This requires only 8 gel lanes and we find that it yields the desired results $88 \%$ of the time. For the $12 \%$ of the cases which fail, it is only necessary to run two additional sets of sequencing reactions, requiring an additional 8 gel lanes.

\section{ACKNOWLEDGEMENT}

This work was supported by NIH grant \# HG00022.

\section{REFERENCES}

1. Weber,J.L. and May,P.E. (1989) Am. J. Hum. Genet. 44, 388-396.

2. Litt,M. and Luty,J.A. (1989) Am. J. Hum. Genet 44, 397-401.

3. Sambrook,J., Fritsch,E.F. and Maniatis,T. (1989) 'Molecular cloning: a laboratory manual'. Cold Spring Harbour Laboratory Press.

4. Yuille,M.A.R., Goudie,D.R., Affara,N.A. and Ferguson-Smith,M.A. (1991) Nucl. Acids Res. 19, 1950.

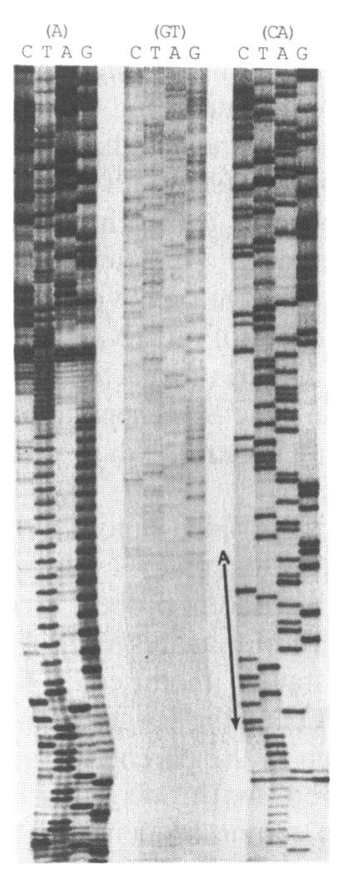

Figure. A subclone with a $5.2 \mathrm{~kb}$ insert which contains a $(\mathrm{CA})_{\mathrm{n}}$ repeat was sequenced with the (CA) and (GT) primer mixes. A unique primer ('A') complementary to the sequence $5^{\prime}$-CCACTCCTCAGAAGATC-3' was obtained from the (CA) primer mix and was used to sequence through the repeat region. 